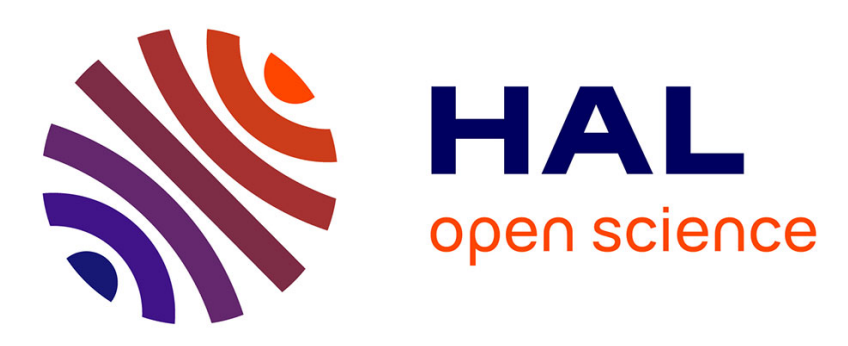

\title{
The cost-effectiveness of supportive periodontal care: a global perspective.
}

\author{
Mark Pennington, Peter Andrew Heasman, Francesca Gaunt, Arndt \\ Guentsch, Saso Ivanovski, Satoshi Imazato, Sunethra Rajapakse, Edith Allen, \\ Thomas Flemmig, Mariano Sanz, et al.
}

\section{To cite this version:}

Mark Pennington, Peter Andrew Heasman, Francesca Gaunt, Arndt Guentsch, Saso Ivanovski, et al.. The cost-effectiveness of supportive periodontal care: a global perspective.. Journal of Clinical Periodontology, 2011, 38 (6), pp.553. 10.1111/j.1600-051X.2011.01722.x . hal-00639395

\section{HAL Id: hal-00639395 https://hal.science/hal-00639395}

Submitted on 9 Nov 2011

HAL is a multi-disciplinary open access archive for the deposit and dissemination of scientific research documents, whether they are published or not. The documents may come from teaching and research institutions in France or abroad, or from public or private research centers.
L'archive ouverte pluridisciplinaire HAL, est destinée au dépôt et à la diffusion de documents scientifiques de niveau recherche, publiés ou non, émanant des établissements d'enseignement et de recherche français ou étrangers, des laboratoires publics ou privés. 


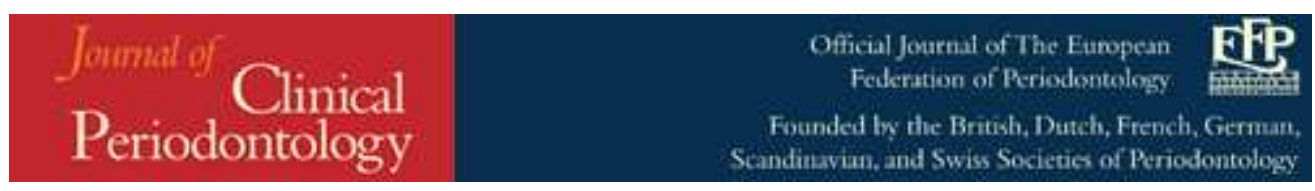

\section{The cost-effectiveness of supportive periodontal care: a global perspective.}

\begin{tabular}{|c|c|}
\hline Journal: & Journal of Clinical Periodontology \\
\hline Manuscript ID: & CPE-01-11-3072 \\
\hline Manuscript Type: & Original Article Clinical Periodontology \\
\hline $\begin{array}{r}\text { Date Submitted by the } \\
\text { Author: }\end{array}$ & 19-Jan-2011 \\
\hline Complete List of Authors: & $\begin{array}{l}\text { Pennington, Mark; London School of Hygiene and Tropical Medicine } \\
\text { Heasman, Peter; School of Dental Sciences, Periodontics } \\
\text { Gaunt, Francesca; Newcastle University, School of Dental Sciences } \\
\text { Guentsch, Arndt; Friedrich-Schiller-University Jena, Department of } \\
\text { Conservative Dentistry, Section Periodontology } \\
\text { Ivanovski, Saso; Griffith University, School of Dentistry and Oral } \\
\text { Health; University of Queensland, School of Dentistry } \\
\text { Imazato, Satoshi; Osaka University, Biomaterials Science } \\
\text { Rajapakse, Sunethra; University of Peradeniya, Faculty of Dental } \\
\text { Sciences; University of Florida, Periodontology } \\
\text { Allen, Edith; Cork University, Restorative Dentistry } \\
\text { Flemmig, Thomas; University of Washington, Periodontics } \\
\text { Sanz, Mariano; Faculty of Odontology, University Complutense of } \\
\text { Madrid } \\
\text { Vernazza, Chris; Newcastle University, School of Dental Sciences }\end{array}$ \\
\hline Topic: & Treatment \\
\hline Keywords: & $\begin{array}{l}\text { health economics, supportive periodontal care, Periodontal disease, } \\
\text { cost effectiveness }\end{array}$ \\
\hline Main Methodology: & Other \\
\hline
\end{tabular}

\section{SCHOLARONE ${ }^{\mathrm{m}}$ Manuscripts}




\title{
Original research
}

\section{The cost-effectiveness of supportive periodontal care: a global perspective}

\author{
Mark Pennington ${ }^{1}$, Peter Heasman ${ }^{2}$, Francesca Gaunt ${ }^{2}$, Arndt Güntsch ${ }^{3}$, Saso Ivanovski ${ }^{4}$, Satoshi \\ Imazato ${ }^{5}$, Sunethra Rajapakse ${ }^{6}$, Edith Allen ${ }^{7}$, Thomas Flemmig ${ }^{8}$, Mariano Sanz ${ }^{9}$, \\ Chris Vernazza ${ }^{1,10}$
}

\section{A paper submitted for consideration for publication in the Journal of Clinical Periodontology}

\author{
${ }^{1}$ London School of Hygiene and Tropical Medicine, UK \\ ${ }^{2}$ School of Dental Sciences, Newcastle University, Newcastle, UK \\ ${ }^{3}$ Department of Conservative Dentistry, University Hospital of Jena, Germany \\ ${ }^{4}$ School of Dentistry and Oral Health, Griffith University, Queensland, Australia \\ ${ }^{5}$ Department of Biomaterials Science, Osaka University Graduate School of Dentistry, Osaka, Japan \\ ${ }^{6}$ Department of Oral Medicine and Periodontology, Faculty of Dental Sciences, University of \\ Peradeniya, Sri Lanka \\ ${ }^{7}$ Department of Restorative Dentistry, Cork University Dental School and Hospital, Ireland \\ ${ }^{8}$ Department of Periodontics, University of Washington, Seattle, USA \\ ${ }^{9}$ Faculty of Odontology, University Complutense, Madrid, Spain \\ ${ }^{10}$ Institute of Health and Society, Newcastle University, Newcastle, UK
}

Key words: health economics, supportive periodontal care, cost-effectiveness, periodontal disease.

Running title: Cost-effectiveness of supportive care

\author{
Address for correspondence: \\ Professor P.A. Heasman \\ School of Dental Sciences \\ Framlington Place \\ Newcastle upon Tyne \\ NE2 4BW, UK. \\ Tel: $+44-191-222-7824$ \\ Fax: +44-191-232-5144 \\ Email:p.a.heasman@ncl.ac.uk
}




\begin{abstract}
Aim: To evaluate the cost-effectiveness of supportive periodontal care (SPC) provided in generalist and periodontal specialist practices under publicly subsidised or private dental care.

Material and Methods: SPC cost data and the costs of replacing teeth were synthesised with estimates of the effectiveness of SPC in preventing attachment and tooth loss and adjusted for differences in clinician's time. Incremental Cost-Effectiveness Ratios were calculated for both outcomes assuming a time horizon of 30 years.
\end{abstract}

Results: SPC in specialist periodontal practice provides improved outcomes but at higher costs than SPC provided by publicly subsidised or private systems. SPC in specialist periodontal practice is usually more cost-effective than in private dental practice. For private dental practices in Spain, UK and Australia, specialist SPC is cost-effective at modest values of attachment loss averted. Variation in the threshold arises primarily from clinician's time.

Conclusion: SPC in specialist periodontal practice represents good value for money for patients (publicly subsidised or private) in the UK and Australia and in Spain if they place relatively modest values on avoiding attachment loss. For patients in Ireland, Germany, Japan and the US, a higher valuation on avoiding attachment loss is needed to justify SPC in private or specialist practices.

\title{
Conflict of interest and source of funding statement
}

The study has no specific source of funding nor was it supported by a grant award. None of the authors or their institutions has any conflict of interest. 


\section{Introduction}

Supportive periodontal care (SPC) comprises professional therapeutic measures that support patients' own efforts to control periodontal infections and avoid re-infections (Lang et al. 2008). There is a substantial literature that supports the importance of SPC in achieving long-term stability in patients with chronic periodontitis. This stability presents as an absence or significant reduction in clinical attachment loss and, from the patient's perspective, maintenance of a functional and aesthetic dentition (Nyman et al. 1975, Axelsson \& Lindhe 1981, Cortellini et al. 1994, Becker et al. 2001, Serino et al. 2001, Preshaw \& Heasman 2005, Eickholtz et al. 2008, Matuliene et al. 2008). The long-term clinical benefit in societal terms, however, will also likely be influenced by the availability of, and access to care, and by ensuring that care provision results in the best use of the available resources.

SPC can be delivered by periodontal specialists or by dentists working with either private or publicly subsidised patients, and the efficiency of SPC can be addressed through an economic evaluation. In a previous, UK-based, study of cost-effectiveness we concluded that SPC delivered in specialist periodontal practice would result in greater periodontal stability and higher tooth survival rates than when SPC is delivered in general dental services. These benefits, however, were more expensive with Incremental Cost-Effectiveness Ratios (ICERs) of approximately $€ 290$ for each extra tooth-year saved and $€ 1500$ per $1 \mathrm{~mm}$ less attachment loss over a 30-year period (Gaunt et al. 2008). The costs averted from preserving the dentition did not entirely offset the costs of SPC provided by periodontal specialists after appropriate discounting (Gaunt et al. 2008).

We acknowledged, however, that these data were specific to the UK systems of dental healthcare and concluded that the model and observations might be sensitive to the costs of SPC in different countries. Consequently, the cost-effectiveness of SPC should be evaluated in different countries and oral health systems.

The objective of this study, therefore, is to evaluate the cost-effectiveness of SPC in different countries and to report ICERs for preserving clinical attachment and avoiding tooth loss based on costs for public, private and specialist periodontal health care systems where those data are available. 


\section{Methods}

\section{Treatment options}

Extensive data on the provision of SPC were collected from Australia, Germany, Ireland, Japan, Spain, Sri Lanka, United Kingdom and the United States. All countries, with the exception of Spain, Ireland and Germany, reported some form of SPC under a state- or employer-subsidised system, although in the US and Australia this system is available only to those on low incomes. Hence, three SPC options were, where possible, evaluated for each country: SPC provided at a general practice under a state supported system; SPC provided at a general practice in the private sector; and SPC provided at a periodontal specialist periodontal practice (Fig.1). The lack of specialist periodontists in Sri Lanka and Japan restricted us to a comparison of state subsidised and private SPC in those countries.

The economic analysis was undertaken from the perspective of the patient and attempted to include all costs falling on the patient as a result of SPC and restorative treatments. The aim was to quantify the benefits of private or specialist SPC to determine which patient values for these outcomes would justify the SPC provisions. We attempted to quantify the full cost to the patient of each SPC option including the opportunity costs of seeking treatment. It was acknowledged that patients typically pay a fraction of the costs of dental care in publicly subsidised systems and the costs falling directly on governments were ignored. In many countries patients using private dental care will have a dental insurance plan, and patient fees at point of use will be reduced or zero. Apart from Germany where it is mandatory, we have assumed that patients do not have private dental insurance. We would expect insurance premiums to broadly reflect patient charges.

Realistic treatment options for patients will depend on whether they access publicly funded dental care (Fig. 1). A patient receiving their routine dental care under the publicly subsidised system (scenario A) had three options: SPC under the publicly subsidised system; private provision of SPC at a generalist practice or SPC at a specialist periodontal practice (where available). Two options were considered for a patient using private regular dental care (scenario B): SPC at their own dental practice or SPC at a specialist periodontal practice. In Germany, SPC is not available under the publicly subsidised system. We considered patients covered by the state insurance (BEMA) system, around $85 \%$ of all patients, and patients with private insurance whose copayments fall under the GOZ tariffs. Patients face the same costs for SPC under both systems, only the costs of replacing lost teeth differ. 


\section{Effectiveness of SPC}

The available data on the long-term outcomes of SPC are limited. Consequently any comparative analysis requires assumptions over the additional effectiveness of alternative/more intensive treatment. Previous comparative analysis (Gaunt et al. 2008) estimated attachment loss and tooth loss over thirty years using published data (clinical reference data) (Axelsson and Lindhe 1981). Axelsson and Lindhe (1981) report attachment loss and tooth loss for patients receiving either 40 or 120 minutes of clinician's time annually. We assumed that the effectiveness of SPC is purely a function of clinician's time and the effectiveness data were adjusted according to the total clinician's time per year for SPC under each dental healthcare system. Exponential functions were selected for this adjustment on the assumption that increasing clinician time would exhibit diminishing marginal increases in effectiveness.

Exponential functions were fitted to the clinical reference data for clinical attachment loss in the first three years of SPC; from the fourth year of SPC; and for tooth loss. A third data point was required to specify an exponential function fitting these criteria and we chose to ensure plausible tooth loss and attachment loss for when clinician time is zero reflecting no SPC provision although data on outcomes in the absence of SPC are limited. Natural history data from Sri Lankan tea plantation workers, with untreated periodontal disease, however, suggest a rate of attachment loss of $0.5 \mathrm{~mm} /$ year and tooth loss of 0.7 per year for those aged 45 years or over and these may provide a reasonable estimate of disease progression in the absence of SPC (Löe et al. 1986). The functions were chosen to ensure values of 0.5 for tooth loss (an estimate below the upper bound for the Sri Lankan population); $0.5 \mathrm{~mm}$ of clinical attachment loss in years $1-3$; and $0.5 \mathrm{~mm}$ of clinical attachment loss in years $4+$ when clinician time was zero. This necessitated applying a kinked function for attachment loss in years 1-3 which assumes a small linear reduction in attachment loss as clinician time increases from 0 to 40 mins followed by an exponential fall in attachment loss as clinician time increases beyond 40 mins. These functions are displayed in Fig. 2 and listed in Appendix 1.

The exponential functions chosen allow for a modest gain in clinical attachment from intensive SPC (Nyman et al. 1975, Axelsson \& Lindhe 1981, Cortellini et al. 1994). A more conservative assumption is that the maximum achievable effectiveness of SPC is to reduce clinical attachment loss to zero. This would reduce the estimated effectiveness of intensive SPC. Data on clinical attachment loss is intended to refer to mean attachment loss at all sites in the mouth, and not attachment loss for a single site. 


\section{Data source for costs and clinician time}

Estimates of patient charges for SPC and clinician's time under publicly subsidised, private and specialist care were collected for the following countries: Australia, Germany, Ireland, Japan, Spain, Sri Lanka, UK and USA. We assumed that all patients in the analysis would receive their periodontal treatment at a specialist periodontal practice. Where SPC is primarily delivered by hygienists rather than dentists or specialists, this was reflected in the relevant costs. Data were also collected on patient charges and times for extractions and prosthetic tooth replacement options for teeth lost through periodontal disease: single implant restorations, removable partial dentures and resinbonded (retained) bridges. Estimates of the proportions of patients receiving each of these replacement options together with those opting for no tooth replacement were made by specialists in each country. Travelling times for patients to generalist and specialist practices were also estimated. Monetary values are for the year 2009.

\section{Calculations of the Effectiveness of SPC}

Total clinician time under each SPC option was summed for each country. This time was used to estimate the effectiveness of SPC in terms of tooth loss and attachment loss using the functions described above and listed in Appendix 1.

\section{Calculations of overall patient costs}

Total patient time (clinical provision and travelling) for SPC was valued against the average wage for that country and added to SPC charges to determine the total cost of SPC from the patient's perspective. The same principle was applied to determine the cost of tooth replacement using each of the prosthetic methods described above. We assumed that a resin bonded bridge required three visits by the patient and that a metal-based denture or a single implant restoration required five. We also assumed that any prosthetic work to replace lost teeth would be undertaken by the patient's regular dentist. An overall cost of tooth replacement was calculated as a weighted mean, weighted by the estimated proportion of each type of prosthetic replacement. Where data were available to differentiate the proportion of replacement restorative treatments chosen under publicly subsidised and private care, these were applied. 
Overall patient costs were considered the sum of costs for SPC and costs for any teeth replaced due to periodontitis. Tooth loss each year was multiplied by the mean cost of prosthetic tooth replacement. These costs were added to the SPC costs to calculate the total cost of SPC and related tooth loss under each option.

\section{Economic Analysis}

The economic evaluation technique used in this study was a cost-effectiveness analysis by which the benefit of SPC was quantified using a single effectiveness measure and the additional cost per unit of additional effectiveness provided as a guide as to whether a more effective treatment is worth paying for. The primary outcome measure for the analysis was clinical attachment loss with a secondary outcome of tooth loss. A tooth-year was recorded for each year a tooth was missing/replaced. Costs and outcomes were summed over thirty years assuming a lifetime of treatment. All costs and outcomes were discounted at a rate of 3.5\% in line with National Institute of Clinical Excellence (NICE, UK 2008) recommendations. Discounting is standard economic practice and reflects time preference: that is, receiving a benefit now being preferred to receiving a benefit at any point in the future; or alternatively, a cost now being preferred less than a cost at any time in the future. The resulting discounted attachment loss was less than the actual attachment loss that would occur over thirty years because attachment loss near the end of the 30-year period is given a reduced weighting. This reflects the fact that it is experienced later in life and hence for a shorter period of time.

In order to evaluate whether an SPC option offers value for money the marginal or incremental cost and marginal benefit of that treatment should be compared to all other reasonable treatment options (Drummond 1997). This was done by calculating the Incremental Cost Effectiveness Ratio (ICER) based on the lifetime (30 year) costs and outcomes for patients under each SPC option. The three SPC options were ranked in order of overall patient cost in each country. Any option that was more expensive and less effective than another SPC option was identified as being dominated. Any option that was more expensive and less effective than any combination of two other SPC options was considered to be extendedly dominated. (In this case privately provided SPC was extendedly dominated if there existed a proportion of patients offered publicly subsidised SPC and a proportion offered specialist SPC for which the total effectiveness for the group was superior and the cost was less than if the whole group had received privately provided SPC.) Dominated and extendedly 
dominated options are never cost-effective whatever the value based on the outcome (another option will always be superior), and hence they are eliminated. The remaining SPC options are ranked in order of effectiveness. The incremental effectiveness, the increase in effectiveness for that option over and above the option below it, was calculated and likewise, the incremental cost. The ICER was calculated for each option above the least effective option by dividing the incremental effectiveness by the incremental cost.

ICERs were calculated for tooth loss and for clinical attachment loss for each country, and then converted to US dollars at Purchasing Power Parity (PPP) exchange rates (OECD 2010). These exchange rates attempt to equate for differences in the cost of goods and services in each country so that the conversion rate equates the 'buying power' of the sum of currency in that country and the equivalent amount in US dollars.

\section{Sensitivity Analysis}

In order to assess how sensitive our cost-effectiveness findings were to assumptions made in modelling the effectiveness of SPC we explored alternative assumptions for the relationship between clinician time and outcomes. Firstly, the clinical reference data (Axelsson and Lindhe 1981) were extrapolated linearly until tooth loss or clinical attachment loss was reduced to zero, at which point no further gains were assumed. Secondly, we explored the sensitivity of the results to the accuracy of the clinical reference data. We applied the same exponential functions but shifted each curve by 0.1 units. Hence tooth loss was assumed to be 0.1 teeth higher for each value of clinician's time. And clinical attachment loss in years 1-3 and years 4+ was assumed to be $0.1 \mathrm{~mm}$ greater for each value of clinician's time. These assumptions impact on both costs (through tooth loss) and effectiveness. ICERs were recalculated under each scenario. A third sensitivity analysis explored the impact of increasing the discount rate for costs and outcomes to $5 \%$. 


\section{Results}

The raw data for cost of SPC, estimated clinician's time to provide SPC over a specified number of patient visits, the cost to the patient of replacing lost teeth and the estimated percentage of patients opting for each restorative treatment option are shown in Table 1 . The estimated costs and outcomes used in the cost-effectiveness analysis are presented in Table 2 . In each country, the provision of SPC delivered in specialist periodontal practice (where available) is more expensive than SPC provided in a general practice under private contract, whereas SPC provided in a general practice in the publicly subsidised system (where available) is the cheapest option. Clinician's time, and hence inferred effectiveness, is highest under specialist care in each country. Further, in general terms, SPC delivered under private payment is afforded more clinician's time than is the case for publicly subsidised treatment although this is not the case in the UK.

\section{Dominated and extendedly dominated options}

For patients accessing publicly subsidised care in the UK, private SPC is dominated by publicly subsidised SPC; private SPC provides the same amount of clinician's time, and hence the same assumed clinical effectiveness but at higher cost than publicly subsidised treatment. For patients using the publicly subsidised sector in Australia, private SPC is extendedly dominated by periodontal specialist care in the domain of clinical attachment loss. The cost per $\mathrm{mm}$ of attachment loss averted in moving from private to specialist care is lower than moving from publicly subsidised to privatelydelivered SPC.

For patients using the publicly subsidised sector in the UK and Australia private SPC is not the optimal treatment whatever value the patient places on the outcome evaluated. Hence this option is discarded and publicly subsidised SPC is compared directly with specialist SPC; the ICER then reports the cost per unit change in outcome in moving from publicly subsidised to specialist-delivered SPC.

\section{Incremental Cost-Effectiveness Ratios}

The ICERs for patients receiving their routine dental care from general dentists in the publicly subsidised sector are shown in Table 3. ICERs are calculated for tooth loss and for clinical attachment loss. The ICERs designated 'private' refer to the cost-effectiveness of SPC provided by in general 
practice under private contract, assuming patients receive routine care in the publicly subsidised system. The ICERs for clinical attachment loss show the additional cost per $\mathrm{mm}$ of attachment loss across all tooth sites prevented by seeking SPC from a private treatment from a general practitioner rather than publicly subsidised treatment. Similarly, the ICERs for tooth loss show the costeffectiveness of SPC with respect to tooth-years as an outcome measure. That is the additional cost per year that a tooth is retained. The cost-effectiveness of SPC provided at a specialist periodontal practice is indicated by the ICERs designated 'specialist'. These ICERs compare specialist periodontist care with the next best care option. Where 'private' SPC is dominated or extendedly dominated the next best option is publicly subsidised SPC.

The ICERs for patients receiving their routine dental care in general practice in the private sector are shown in Table 4. For patients from the private sector all ICERs refer to the cost-effectiveness of SPC provided at a specialist periodontal practice compared to SPC delivered by their private general practitioner.

\section{Publicly subsidised patients in the UK and Australia}

In the UK, a publicly subsidised system is used by the majority of the population. These patients should seek specialist SPC if they value the prevention of attachment loss at more than $£ 950$ (1450 international dollars) per $\mathrm{mm}$ avoided over 30 years. Any patient valuing the retention of teeth (compared to prosthetic replacement) at more than $£ 200$ (300 international dollars) per year per tooth should also seek SPC from a specialist periodontist. The data and implications are similar in Australia, although in this country publicly subsidised care is only available to a minority of the population who are financially disadvantaged, and for those patients these thresholds may represent significant sums of money.

\section{Publicly subsidised patients in the US}

The publicly subsidised system in the US is also restricted to disadvantaged patients. Consequently the high threshold for the cost-effectiveness of specialist SPC is unlikely to represent value for money for these recipients. Privately-delivered SPC, however, is not dominated in the US. For patients accessing the publicly subsidised system who are prepared to pay between $\$ 2,500$ and $\$ 5,000$ for 
each $\mathrm{mm}$ of attachment loss averted, or who value retaining teeth at $\$ 590$ to $\$ 2,250$ per tooth year, private SPC represents good value for money.

\section{Publicly subsidised patients in Japan and Germany}

The generous provision of clinician's time and hence assumed greater effectiveness of publicly subsidised SPC in Japan results in a very high ICER for private SPC (the gain in effectiveness in moving to private SPC is relatively small). Only patients placing high values on avoiding attachment loss or retaining their dentition are likely to regard private SPC as value for money. A similar result is observed in Germany where the high effectiveness of private SPC results in little additional gain, and hence a high cost-effectiveness threshold for specialist SPC. ICERs for Germany are virtually identical whether the patient is covered by BEMA (state provided) or GOZ (privately provided) insurance.

\section{Publicly subsidised patients in Sri Lanka}

The ICERs for private SPC in Sri Lanka are notably small. For many patients accessing dental care in the developing world funds may be extremely limited. Nevertheless, the ICER is a valuable guide to whether patients should access private SPC in countries such as Sri Lanka.

\section{Private patients in Australia, Spain and the UK}

For private patients in the UK, Australia and Spain the threshold for the cost-effectiveness of specialist SPC is modest. SPC is good value for money for patients prepared to pay at least $f 700(1,050$ international dollars) in the UK and 1,600 euros in Spain (2,100 international dollars) per mm of attachment loss avoided during their lifetime.

\section{Private patients in the US and Ireland}

The threshold for the cost-effectiveness of specialist SPC is higher in the US and Ireland. In Ireland this is because of the high specialist costs, whereas in the US the generous provision of clinician's time in the private sector reduces the incremental effectiveness of specialist SPC. Clearly some patients in the US and Ireland will value avoiding attachment loss at less than ca. $\$ 5,000$ per $\mathrm{mm}$ and these patients would be best advised to continue to receive care from their private general dentist. 


\section{Sensitivity Analyses}

Table 5 presents the estimates of the effectiveness of SPC and the ICERs calculated after applying a linear extrapolation of the clinical reference data (Axelsson and Lindhe 1981). Apart from values for the US the impact on the ICERs calculated for the primary outcome measure is small. The impact on the secondary outcome measure is larger with significant changes to the ICERs for tooth loss in Germany, Japan and the US. The impact of the linear extrapolation is most significant for tooth loss at bigger values of clinician's time because this is where the divergence between the exponential and linear extrapolations is largest. The impact of increasing tooth loss and clinical attachment loss by 0.1 unit for all values of clinician's time is minuscule. This is not surprising as the economic analysis considers the relative performance of SPC in different sectors. The impact of discounting at $5 \%$ was small, hence the results can be considered to be valid for discount rates in the range $3-5 \%$.

\section{Discussion}

Our analysis suggests that the additional costs of seeking periodontal SPC from either private or periodontal specialist providers compared to the cheapest available SPC are not outweighed by the savings generated by increased tooth retention. In fact, comparison of the results for Germany under the BEMA and GOZ tariffs for tooth replacement indicate that these costs have a relatively minor impact on cost-effectiveness. This, however, does not mean that private or specialist periodontal treatment is not cost-effective. The additional costs are certainly justified if the patient places more value on the outcome than the minimum value indicated by the ICER. The value of private or specialist SPC is relative to the options available to the patient; where publicly subsidised or private treatment from a generalist is effective, the ICER for specialist SPC is likely to be high. Hence it is appropriate to consider separately the cost-effectiveness of SPC for patients accessing state-supported or private dental care.

The ICERs provide an important indication of which treatment options provide value for money for patients and allow simple comparisons to be made across countries. Calculation of ICERs requires an assumption that each $\mathrm{mm}$ of attachment loss averted is equally valued although in reality, patients may place a higher value per $\mathrm{mm}$ of attachment loss where the existing loss is higher and further loss is likely to compromise a functional dentition. It is also important to keep in mind that clinical 
attachment loss is gradual and that differences in outcomes will only manifest themselves fully towards the end of the patient's lifetime. The discounting of attachment loss, a process which places a lower weight on attachment loss occurring later in life, helps to account for this. The calculation of ICERs using discounted attachment loss provides an indication of which treatment option provides the best value for money for the patient based on that patient's valuation of the clinical outcome. The ICERs indicate that private treatment in the UK and Australia is never the best option in terms of value for money. In contrast, private treatment in Germany appears to be highly effective, resulting in very high thresholds before specialist provision can be considered good value for money.

In the absence of good quality clinical data on each SPC management option in each country, assumptions on the effectiveness of treatment have to be made in order to evaluate costeffectiveness. This analysis is based on an assumption that the effectiveness of SPC is a function of total clinician's time. This is not to say that time is the only aspect of treatment to have clinical value, but that clinician's time is a good predictor of overall effectiveness of SPC. The exponential functions used in the base case make plausible assumptions over outcomes arising from differences in clinician's time in different countries. Indeed, the negative attachment loss values and long-term periodontal benefit associated with the higher clinician times may be the overriding consideration and suggests that there would be no difference in treatment effectiveness if all clinicians in all practices were allotted the same time for provision of care. The sensitivity analysis suggests that the results for the primary outcome measure are reasonable robust to alternative assumptions. The results for the secondary outcome measure are more strongly affected. It is apparent that further long term studies of the effectiveness of specialist SPC compared to general practice are needed to properly inform considerations of cost-effectiveness. 


\section{Conclusion}

Across different countries, SPC provided by periodontal specialists results in less clinical attachment loss but at an increased overall cost when compared to SPC provided in publicly subsidised or private practices. In general, for patients routinely accessing publicly subsidised care, private SPC is not costeffective; patients placing a higher value on avoiding attachment loss should seek SPC from a specialist periodontist. In Sri Lanka, however, where periodontal specialist SPC is unavailable, SPC in private practice is cost-effective for patients placing a relatively modest value on avoiding attachment loss. The threshold of cost-effectiveness of specialist SPC for patients in private practice varies from $\$ 1,000$ to $\$ 13,000$ per $\mathrm{mm}$ of attachment loss avoided over thirty years across different countries. This variation in is driven primarily by the clinician's time, and hence assumed effectiveness, provided in private practice.

\section{Acknowledgements}

The authors wish to thank Mrs Susan Johnstone for her help in preparing the manuscript. 


\section{References}

Axelsson, P. \& Lindhe, J. (1981) The significance of maintenance care in the treatment of periodontal disease. Journal of Clinical Periodontology 8, 281-294.

Becker, W., Becker, B.E., Caffesse, R., Kerry, G., Ochsenbein, C., Morrison, E. \& Prichard, J. (2001) A longitudinal study comparing scaling, osseous surgery and modified Widman procedures: results after 5 years. Journal of Periodontology 72, 1675-1684.

Cortellini, P., Pino-Prato, G. \& Tonetti, M. (1994) Periodontal regeneration of human infra-bony defects (V). Effect of oral hygiene on long-term stability. Journal of Clinical Periodontology 21, 606610.

Drummond, M.F., O'Brien, B.J., Stoddart, G.L. \& Torrance, G.W. (1997) Methods for the economic evaluation of healthcare programmes. $2^{\text {nd }}$ Edition. Oxford. Oxford University Press.

Eickholtz, P., Kaltschmitt, J., Berbig, J., Reitmer, P. \& Pretzl, B. (2008) Tooth loss after active periodontal therapy 1: patient-related factors for risk, prognosis and quality of outcome. Journal of Clinical Periodontology 35, 165-174.

Gaunt, F., Devine, M., Pennington, M., Vernazza, C., Gwynnett, E., Steen, N. \& Heasman, P. A. (2008) The cost-effectiveness of supportive periodontal care for patients with chronic periodontitis. Journal of Clinical Periodontology 35, 67-82.

Lang, N.P., Brägger, U., Salvi, G.E. \& Tonetti, M.S. (2008) Supportive Periodontal Therapy. In: Clinical Periodontology and Implant Dentistry, 5th Edition (Editors Lindhe, J., Lang, N.P., \& Karring, T.) pp.349-62, Wiley-Blackwell, Oxford.

Löe, H., Ånerud, A., Boysen, H. \& Morrison, E. (1986) Natural history of periodontal disease in man. Rapid, moderate and no loss of attachment in Sri Lankan laborers 14 to 46 years of age. Journal of Clinical Periodontology 13, 431-445.

Matuliene, G., Salvi, G. E., Pjetursson, B. E., Schmidlin, K., Bragger, U., Weber, H. P. \& Lang, N. P. (2008) Influence of residual pockets on the progression of periodontitis and tooth loss: Results after eleven years of maintenance care. Journal of Clinical Periodontology 35, 685-695.

Nice (2008). Guide to the methods of technology appraisal. National Institute for Health and Clinical Excellence, 2008. Publication N1618

http://www.nice.org.uk/media/B52/A7/TAMethodsGuideUpdatedJune2008.pdf Accessed September 2010.

Nyman, S., Rosling, B. \& Lindhe, J. (1975) Effect of professional tooth cleaning on healing after periodontal surgery. Journal of Clinical Periodontology 2, 80-86.

Organisation for Economic Cooperation and Development, statistics directorate, Purchasing Power Parities

http://www.oecd.org/std/ppp Accessed September 2010. 
Preshaw, P. M. \& Heasman, P. A. (2005) Periodontal maintenance in a specialist periodontal clinic and in general dental practice. Journal of Clinical Periodontology 32, 280-286.

Serino, G., Rosling, B., Ramberg, P., Socransky, S. S. \& Lindhe, J. (2001) Initial outcome and long-term effect of surgical and nonsurgical treatment of advanced periodontal disease. Journal of Clinical Periodontology 28, 910-916.

\section{Clinical Relevance}

Scientific rationale for the study: Patient decision making should be supported by evidence of the cost-effectiveness of treatments.

Principal finding: Specialist SPC is more effective than SPC provided in state or private practices but the additional cost is not entirely offset through reduced costs of tooth replacement. Only in the US is SPC in private practice a cost-effective option.

Practical implications: Based on typical SPC provision for a range of dental care systems the value patients must place on avoiding further attachment loss must be considered if specialist SPC is to represent good value for money.

\section{Appendix 1}

$c=$ total clinician time per year in minutes

Tooth loss as a function of clinician time:

Tooth loss $=0.47 \exp (-0.0423 c)+0.03$

Clinical attachment loss as a function of clinician time in the first three years:

$C A L=0.5-0.00167 c$ for $c<40$

$C A L=1.362 \exp (-0.025 c)-0.0678$ for $c>40$

Clinical attachment loss as a function of clinician time, year four onwards:

CAL $=0.526 \exp (-0.0251 c)-0.026$ 


\section{Address for correspondence:}

Professor P.A. Heasman

School of Dental Sciences

Framlington Place

Newcastle upon Tyne

NE2 4BW, UK.

Tel: +44-191-222-7824

Fax: +44-191-232-5144

Email: p.a.heasman@ncl.ac.uk 


Sri Lanka USA Spain Japan Ireland UK Germany

(Rupee) (Dollar) (Euro) (Yen)

(Euro)

(Pound) (Euro)

Australia

Supportive Periodontal Care

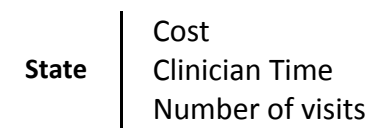

$\begin{array}{rrrr}0 & 50.0 & \text { na } & 2,958 \\ 20 & 45.0 & \text { na } & 30 \\ 2 & 1.5 & \text { na } & 4\end{array}$

$\begin{array}{ll}\text { na } & 10 \\ \text { na } & 20\end{array}$

10 na

na

0.0

Number of visits

\begin{tabular}{l|l} 
Private & Cost \\
Clinician Time \\
Number of visits
\end{tabular}

$\begin{array}{rrr}1,000 & 106.0 & 60.0 \\ 45 & 45.0 & 30.0 \\ 4 & 2.0 & 1.5\end{array}$

15,000

$\begin{array}{lll}80 & 37 & 70\end{array}$

na

30.0

10

Cost to patient of replacement of lost teeth

\begin{tabular}{|c|c|c|c|c|c|c|c|c|c|}
\hline \multirow{4}{*}{ State } & Extraction only & 0 & 33 & na & 1,716 & na & 11 & 0 & 0 \\
\hline & Bridgework & 10,000 & 2,086 & na & 11,865 & na & 129 & 370 & 0 \\
\hline & Removeable prosthesis & 0 & 481 & na & 7,605 & na & 64 & 80 & 0 \\
\hline & Implant & 50,000 & 3,327 & na & 350,000 & na & 2,000 & 1,960 & na \\
\hline \multirow{4}{*}{ Private } & Extraction only & 500 & 121 & 50.0 & 12,000 & 100 & 60 & 20 & 140 \\
\hline & Bridgework & 10,000 & 2,086 & 250.0 & 300,000 & 1,000 & 600 & 880 & 1600 \\
\hline & Removable prosthesis & 3,000 & 1,419 & 250.0 & 50,000 & 400 & 350 & 340 & 1000 \\
\hline & Implant & 50,000 & 3,327 & $1,200.0$ & 400,000 & 4,500 & 2,000 & 2,400 & 4000 \\
\hline \multirow{4}{*}{$\begin{array}{l}\text { Time } \\
\text { Taken }\end{array}$} & Extraction only & 15 & 20 & 30.0 & $35(60) *$ & 30 & 20 & 28 & 30 \\
\hline & Bridgework & 45 & 200 & 60.0 & $130(240)^{*}$ & 90 & 100 & 136 & 120 \\
\hline & Removable prosthesis & 120 & 145 & 60.0 & 150(180)* & 45 & 80 & 92 & 75 \\
\hline & Implant & 120 & 224 & 180.0 & $270(480)^{*}$ & 165 & 230 & 488 & 240 \\
\hline
\end{tabular}

\section{Proportion of patients selecting prosthesis}

\begin{tabular}{|c|c|c|c|c|c|c|c|c|c|}
\hline \multirow{4}{*}{ State } & Extraction only & $5 \%$ & $23 \%$ & na & $8 \%$ & na & $15 \%$ & $14 \%$ & $40 \%$ \\
\hline & Bridgework & $15 \%$ & $31 \%$ & na & $65 \%$ & na & $45 \%$ & $51 \%$ & $15 \%$ \\
\hline & Removable prosthesis & $75 \%$ & $30 \%$ & na & $13 \%$ & na & $40 \%$ & $28 \%$ & $45 \%$ \\
\hline & Implant & $5 \%$ & $16 \%$ & na & $13 \%$ & na & $5 \%$ & $7 \%$ & $0 \%$ \\
\hline \multirow{4}{*}{ Private } & Extraction only & $5 \%$ & $10 \%$ & $20 \%$ & $10 \%$ & $33 \%$ & $10 \%$ & $14 \%$ & $25 \%$ \\
\hline & Bridgework & $15 \%$ & $40 \%$ & $10 \%$ & $40 \%$ & $22 \%$ & $20 \%$ & $51 \%$ & $30 \%$ \\
\hline & Removable prosthesis & $75 \%$ & $10 \%$ & $30 \%$ & $10 \%$ & $37 \%$ & $25 \%$ & $28 \%$ & $30 \%$ \\
\hline & Implant & $5 \%$ & $40 \%$ & $40 \%$ & $40 \%$ & $7 \%$ & $20 \%$ & $7 \%$ & $15 \%$ \\
\hline Travel & Generalist & 30 & 15 & 30 & 30 & 60 & 30 & 20 & 15 \\
\hline Time & Specialist & 60 & 45 & 45 & 60 & 120 & 60 & 60 & 45 \\
\hline
\end{tabular}

* figures in brackets refer to private treatment na - not applicable

Table 1 Data collected from each country: The cost and delivery of supportive periodontal care; cost of replacing missing teeth; and the estimated proportion of patients choosing each restorative treatment option. Costs in local currencies so cross column comparisons not possible. 


\begin{tabular}{|c|c|c|c|c|c|c|c|c|}
\hline & $\begin{array}{c}\begin{array}{c}\text { Sri Lanka } \\
\text { (Rupee) }\end{array} \\
\end{array}$ & $\begin{array}{c}\text { USA } \\
\text { (Dollar) }\end{array}$ & $\begin{array}{l}\text { Spain } \\
\text { (Euro) }\end{array}$ & $\begin{array}{c}\text { Japan } \\
\text { (Yen) }\end{array}$ & $\begin{array}{l}\begin{array}{l}\text { Ireland } \\
\text { (Euro) }\end{array} \\
\end{array}$ & $\begin{array}{c}\text { UK } \\
\text { (Pound) }\end{array}$ & $\begin{array}{c}\text { Germany } \\
\text { (Euro) }\end{array}$ & $\begin{array}{c}\text { Australia } \\
\text { (Dollar) }\end{array}$ \\
\hline \multicolumn{9}{|c|}{ Treatment costs for SPC (inc travel) } \\
\hline State & 76 & 116 & na & 20,162 & na & 46 & na & 41 \\
\hline Private & 4,229 & 267 & 110 & 59,058 & 239 & 101 & 270 & 234 \\
\hline Specialist & na & 579 & 425 & na & 1,036 & 299 & 568 & 511 \\
\hline \multicolumn{9}{|l|}{ Cost of tooth replacment } \\
\hline State & 6,457 & 1424 & na & 64,583 & na & 239 & 414 & 0 \\
\hline Private & 4,480 & 2,431 & 639 & 304,943 & 848 & 661 & 782 & 1,507 \\
\hline \multicolumn{9}{|l|}{ Hygienist time (min) } \\
\hline State & 40 & 68 & na & 120 & na & 40 & & 45 \\
\hline Private & 80 & 90 & 45 & 225 & 60 & 40 & 113 & 60 \\
\hline Specialist & & 180 & 113 na & & 240 & 120 & 158 & 113 \\
\hline \multicolumn{9}{|l|}{ Tooth loss per year } \\
\hline State & 0.117 & 0.057 & na & 0.033 & na & 0.117 & na & 0.100 \\
\hline Private & 0.030 & 0.040 & 0.100 & 0.030 & 0.067 & 0.117 & 0.034 & 0.067 \\
\hline Specialist & na & 0.030 & 0.034 & na & 0.030 & 0.033 & 0.031 & 0.034 \\
\hline \multicolumn{9}{|c|}{ Attachment loss per year: years 1-3 } \\
\hline State & 0.433 & 0.184 & na & 0.000 & na & 0.433 & na & 0.374 \\
\hline Private & -0.053 & 0.076 & 0.374 & -0.063 & 0.236 & 0.433 & 0.014 & 0.236 \\
\hline Specialist & na & -0.053 & 0.014 & na & -0.064 & 0.000 & -0.041 & 0.014 \\
\hline \multicolumn{9}{|c|}{ Attachment loss per year: year 4 onwards } \\
\hline State & 0.167 & 0.071 & na & 0.000 & na & 0.167 & na & 0.144 \\
\hline Private & -0.020 & 0.029 & 0.144 & -0.024 & 0.091 & 0.167 & 0.005 & 0.091 \\
\hline Specialist & na & -0.020 & 0.005 & na & -0.025 & 0.000 & -0.016 & 0.005 \\
\hline
\end{tabular}

Table 2 Cost and effectiveness data. Data are from 8 countries and for patients receiving SPC in state and private sectors as well as from periodontal specialists Costs in local currencies so cross column comparisons not possible. na - not applicable 


\begin{tabular}{|c|c|c|c|c|c|c|c|}
\hline & \multirow{2}{*}{$\begin{array}{l}\text { Sri Lanka } \\
\text { (Rupee) }\end{array}$} & \multirow{2}{*}{$\begin{array}{c}\text { USA } \\
\text { (Dollar) } \\
\end{array}$} & \multirow{2}{*}{$\begin{array}{l}\text { Spain } \\
\text { (Euro) }\end{array}$} & \multirow{2}{*}{$\begin{array}{l}\text { Japan } \\
\text { Loca } \\
\text { (Yen) }\end{array}$} & \multirow{2}{*}{$\begin{array}{l}\text { Ireland } \\
\text { Currencies }\end{array}$} & \multirow{2}{*}{$\begin{array}{cc}\text { UK } & \text { Germany } \\
& \\
\text { (Pound) } & \text { (Euro) } \\
\end{array}$} & \multirow{2}{*}{$\begin{array}{r}\text { Australia } \\
\text { (Dollar) }\end{array}$} \\
\hline & & & & & & & \\
\hline \multicolumn{8}{|l|}{ Tooth Loss } \\
\hline Private & 3,400 & $590 n$ & & $1,000,000$ & na & D & 450 \\
\hline Specialist & na & $2,250 n$ & & na & na & 200 & 650 \\
\hline \multicolumn{8}{|l|}{ Clinical attachment loss } \\
\hline Private & 17,200 & 2,450 & na & $1,300,000$ & na & D & ED \\
\hline Specialist & na & 4,850 & na & na & na & 950 & 2,700 \\
\hline \multicolumn{8}{|c|}{ Converted to USD at purchasing power parity } \\
\hline Tooth Loss & & & & & & & \\
\hline Private & $\$ 100$ & $\$ 590$ & na & $\$ 8,800$ & na & D & $\$ 300$ \\
\hline Specialist & na & $\$ 2,250$ & na & & na & $\$ 300$ & $\$ 450$ \\
\hline \multicolumn{8}{|l|}{ Clinical attachment loss } \\
\hline Private & $\$ 450$ & $\$ 2,450$ & na & $\$ 11,050$ & na & $\mathrm{D}$ & ED \\
\hline Specialist & na & $\$ 4,850$ & na & na & na & $\$ 1,450$ & $\$ 1,850$ \\
\hline
\end{tabular}

Table 3 Incremental Cost - Effectiveness Ratios (ICERS)

For patients who receive their routine dental care with a state health care system (Scenario A in Figure 2). Data presented in national currency and when converted to $\$ \mathrm{US}$ at purchasing power parity. na - not applicable 
Table 4 Incremental Cost - Effectiveness Ratios (ICERS)

For patients who receive their routine dental care in the private sector (Scenario B in Figure 2)

Data presented in national currency and when converted to \$US at purchasing power parity

na - not applicable

* GOZ - Gebührenordnung für Zahnärzte

* BEMA - Bewertungsmaßstab zahnärztlicher Leistungen

\begin{tabular}{|c|c|c|c|c|c|c|c|c|c|}
\hline & & & & & & \multirow[b]{2}{*}{ UK } & \multirow{2}{*}{\multicolumn{2}{|c|}{ Germany }} & \multirow[b]{2}{*}{ Australia } \\
\hline \multirow{2}{*}{ Publicly funded system } & \multirow[t]{3}{*}{ Sri Lanka } & \multirow[t]{2}{*}{ USA } & \multirow[t]{2}{*}{ Spain } & \multirow[t]{2}{*}{ Japan } & Ireland & & & & \\
\hline & & & & & & & & & \\
\hline & \\
\hline Private & $\$ 100$ & ED & - & $\$ 750$ & - & D & - & - & ED \\
\hline $\begin{array}{r}\text { Specialist } \\
\end{array}$ & - & $\$ 300$ & - & - & - & $\$ 300$ & - & - & $\$ 350$ \\
\hline \multicolumn{10}{|l|}{ Clinical attachment loss } \\
\hline Private & $\$ 500$ & $\$ 2,000$ & - & D & - & D & - & - & ED \\
\hline Specialist & - & $\$ 2,850$ & - & - & - & $\$ 1,450$ & - & - & $\$ 1,800$ \\
\hline \multicolumn{10}{|c|}{ Patients accessing private care } \\
\hline Tooth Loss & & $\$ 200$ & $\$ 400$ & - & $\$ 600$ & $\$ 200$ & $\$ 600$ & $\$ 600$ & $\$ 350$ \\
\hline Clinical attachment loss & & $\$ 2,000$ & $\$ 2,050$ & & $\$ 4,700$ & $\$ 1,050$ & $\$ 16,050$ & $\$ 17,000$ & $\$ 1,450$ \\
\hline
\end{tabular}

Table 5 Sensitivity Analysis for the linear extrapolation of effectiveness data from Axelsson and Lindhe Data presented in \$US at purchasing power parity.

* GOZ - Gebührenordnung für Zahnärzte

* BEMA - Bewertungsmaßstab zahnärztlicher Leistungen 


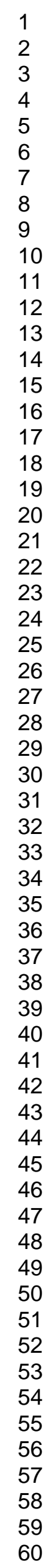




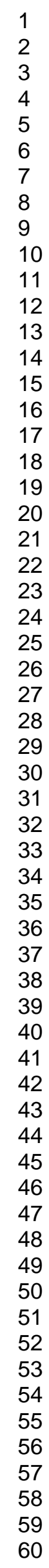

Journal of Clinical Periodontology - PROOF 
Scenario A

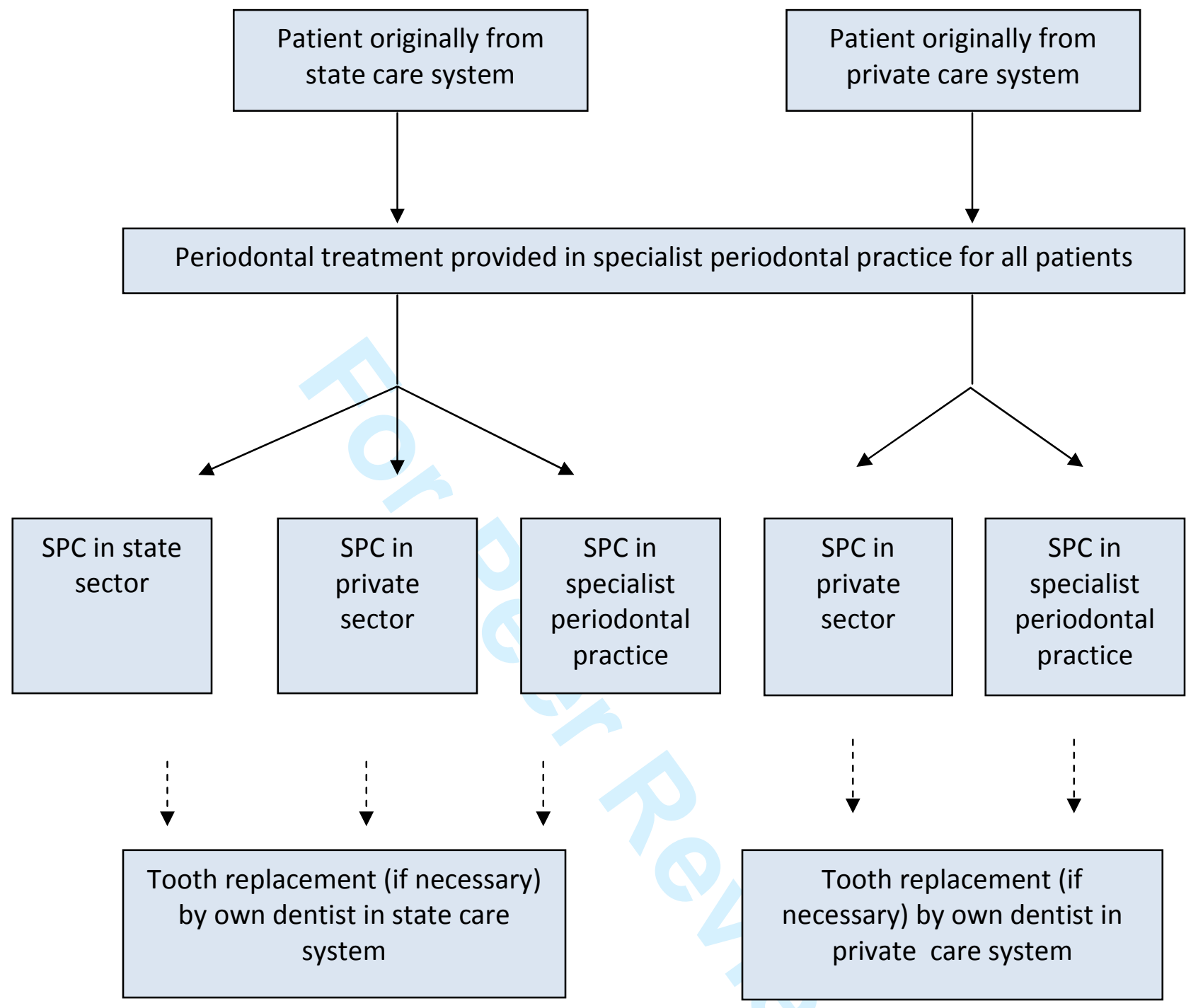

\section{Figure 1}

Possible patient scenarios for overall strategies of periodontal care provision. It is assumed that all patients receive their periodontal treatment at a specialist periodontal practice. For long-term care there are options for receiving supportive periodontal care (SPC) at the patients' own dental practice in the state or private systems or at a specialist periodontal practice. It is assumed that:

(i) restorative care for tooth replacement will be from the patients' own dentists;

(ii) a patient whose regular dental care is provided in the private sector will not defer to a state care system for long-term SPC (scenario B). 


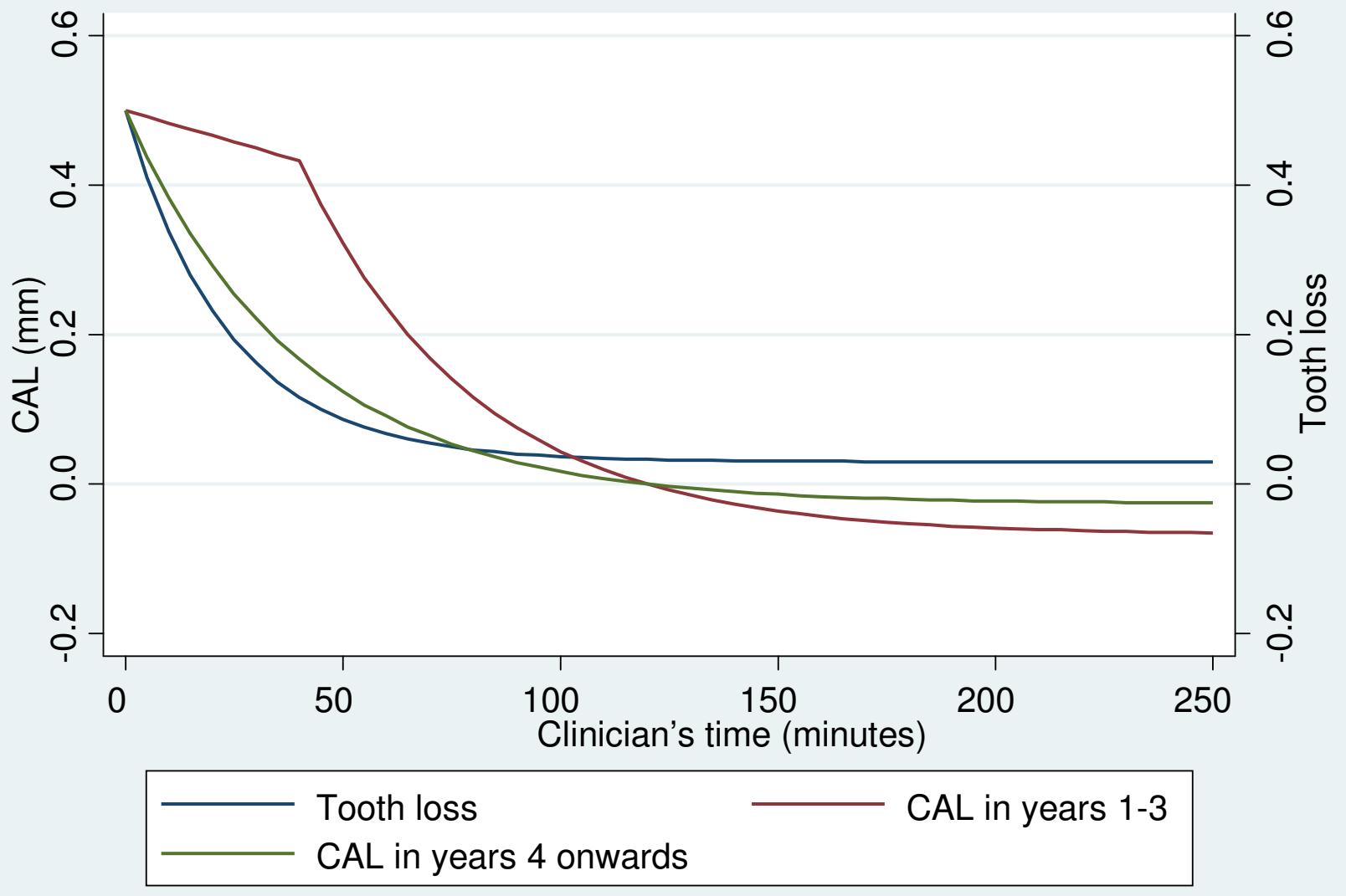

Figure 2.

Clinical attachment loss (CAL) and tooth loss as a function of the clinician's time in providing SPC. (See text for detailed explanation) 